\title{
The Development of Aurilio Games to Facilitate the Ear Training of Early Childhood
}

\author{
Resa Respati* \\ Pendidikan Guru Sekolah Dasar \\ Universitas Pendidikan Indonesia \\ Bandung, Indonesia \\ *respati@upi.edu
}

\author{
Eli Apriyaningsih, Heri Yusuf Muslihin \\ Pendidikan Guru Pendidikan Anak Usia Dini \\ Universitas Pendidikan Indonesia \\ Bandung, Indonesia \\ heriyusuf@upi.edu
}

\begin{abstract}
Music learning benefits various aspects of children's development, especially in hearing abilities and sharpness. Thus, music learning began to be applied to early childhood education in the standard of children's developmental attainment and indicators of children's developmental attainment in the curriculum in Indonesia. The use of solfeggio methods in early childhood musical development exercises becomes a particular facility. But in the implementation of early childhood music learning is encountered problems, namely the limitations of music learning media that impact the results of learning itself. Therefore, this research was conducted with the aim of describing the design, feasibility, and implementation of aurilio gaming media to facilitate the ear training of early childhood. The research method used is the Reeves Design Based Research (DBR). Implementation was carried out with product trials of 2 groups of children with a sample number of 26 children. Aurilio's game media success data was obtained in facilitating early childhood ear training of $70 \%$ and $72 \%$ in each group. The product of this research is an educative game application used to facilitate ear training that develops auditory and verbal aspects of early childhood. The product is equipped with learning scenarios, handbooks for teachers and parents and observation guidelines to evaluate the results of the game to make it easier to use it.
\end{abstract}

Keywords—solfeggio, music, early childhood, listening, ear training

\section{INTRODUCTION}

Children's development can be influenced by the presentation of musical elements during school learning [1], but the majority of teachers still regard music as entertainment and skills, not as an effort to develop various aspects of children's development. Teachers still have difficulty in applying music learning at the early childhood education level due to limited procurement of learning media for music learning. In fact, teachers recognize that children become more interactive when presented elements of music in learning and will be more optimal when there is music logging media in school.

As we know that children love to play with rhythm, musical instruments, singing and others in close relationship with music. Music is closely related to the senses of the ear, and childhood is a critical period of auditory learning. Thus, it is important to be able to train the hearing a sharpness of children early on. Speaking of these opportunities, there is a method of music learning related to the optimization of hearing a sharpness, the Solfeggio method. The Solfeggio method is a musical method developed by Zoltan Kodaly in the form of exercises of hearing ability or musical hearing a sharpness, both rhythmic precision and tone accuracy. The solfeggio method consists of three stages, namely ear training, sight singing, and sight reading [2,3].

In addition to the selection of the right methods, the use of learning media is also an important component in the success of learning achievements [4]. Multimedia has been a factor in learning success in recent years and gaming has become the most accepted and liked multimedia by children [5]. There are many multimedia game-shaped games developed to optimize aspects of early childhood development, such as game development for literacy, storytelling games, vocabulary games for early childhood literacy aspects. But multimedia development research in the form of games to train hearing skills is still very limited [6,7].

Therefore, researchers feel the need to develop multimediabased games to facilitate ear training for early childhood. So the game deserves to be used as a learning medium in an effort to achieve hearing ability as well as the demands of standard child developmental attainment levels and indicators of children's developmental achievement in the early childhood education curriculum in Indonesia.

\section{METHODS}

This research aims to develop multimedia based video games educative, to facilitate the ear training of early childhood by using solfeggio music learning methods, therefore researchers take design based research (DBR) method, the purpose of design based research method is to design, develop, and test the feasibility of a product to solve problems in learning. So the DBR method is suitable for researchers to use [8]. 
Participants and research places that played a role in this study were teachers and early childhood kindergarten level, which indicated facilitating music learning media with participants namely 26 Children and 2 classroom teachers.

Research instruments to be used using qualitative approaches, which researchers become research instruments, to analyze data sources and examine them in depth. Then, in a quantitative approach using interview sheet instruments, to know the field conditions and input materials of product development, validity sheets to validate the validity and feasibility of products by experts in the field of music, media, and pedagogics before field trials, observation sheets, teacher response questionnaires are used to find out the usability aspects of the media tested, and documentation study sheets to archive findings in the form of written data recorded, government theories and regulations.

Data collection is done through interviews, in order to obtain field needs and components that must be met in multimedia development from experts. Then, expert validation is done to music experts, media experts and pedagogy expert to obtain product eligibility before it is implemented field. In addition, researchers also used the Observation sheet of Child Ear training Ability, to know the use of products in facilitating early childhood ear training. Furthermore, teacher response checks are used to determine the usability aspects of the developed product, and the study documentation, used to identify and analyze theories, regulations, data archive as the basis for product development.

The data analysis in this study is data reduction, done by selecting and collecting the necessary data and sideways data that is not needed. This is to make the research data more focused and targeted. Then, the data display presentation data is presented in the form of a text description and presented also in the form of a table, and conclusion drawing /verification, drawing conclusions and verification of the data that has been obtained. The final result of the data analysis in this study is the conclusion of the feasibility of flash-based learning media to facilitate ear training of early childhood

Ethical issues, used to explain the positive impact sparked by the study for participants physically and psychologically as a solution to potential negative impacts. Things that may happen during the study, including the need for legal research and the anxiety of the atmosphere are conducive at the time of the trial.

\section{RESULTS AND DISCUSSION}

\section{A. Product Development}

Based on the results of the study, there are several things to note in game development to facilitate ear training of early childhood. Media development is based on theoretical studies, problem findings and field needs. The combination of multimedia elements, namely images, sounds, and animations can add interactivity [9] and appeal in designing games for early childhood. The games developed are based on solfeggio methods and are adapted to the developmental characteristics of early childhood listening. Considering this, game development is done by paying attention to the solfeggio stages that early childhood can master, namely 1) Ear training; and 2) Sight singing. Thus, in this study, six points were set on the basis of the development of accompaniment music, namely:

1) Material development in multimedia based on solfeggio method: Before conducting multimedia development, researchers first studied music learning methods suitable for developing aspects of music art and at the same time developing auditory and verbal children. From various methods of music learning obtained a very relevant method, namely the solfeggio method developed by Zoltan Kodally. This method consists of three main stages, namely ear training stage, with the aim of learning to train hearing sensitivity to sound. Then sight singing, with the aim of learning the child is able to perceived the sound heard with his oral abilities. And sight reading, with the aim of learning children are able to read and write musical scores[10-12].

Understanding this, researchers adapted the solfeggio method by making several adjustments as well as the characteristics and tasks of early childhood development. At an early age, the child's developmental tasks have been able to identify sounds and simulate the sounds they hear, but the child has not yet achieved the ability to read symbols. Therefore, based on the results of discussions with music experts and pedagogical experts the researchers determined in the development of the game aurilio will contain only two stages, namely the ear training stage which focuses on the ability to identify sounds and sight singing that focuses on the ability to simulate sound with both sound and movement.

In Aurilio Game, the ear training stage is at level one, namely the Know The Sound level. The level of the game is conditioned by presenting sounds from the child's environment, such as animal sounds, vehicles, and musical instruments as a source of sound to train the child's ability to discriminate against sounds and identify the number of sounds as well as high-low sounds. While the sight singing stage is at levels two and three, namely the Level of Assimilating Syllables and the Level of Simulating Symbols. Level two is conditioned by using syllables that play according to the beats of the mentronome to increase the seeding of the child's words and train the verbal aspects of the child. Kemudan for level three is presented syllables to multiplie symbols of objects and symbols of movement played according to the beat of the metronome.

2) Game development using Adobe Flash professional CS6: Designing and editing animation-based multimedia needs to use software that supports product success to match expectations. One animation software that has an advantage in terms of usage is Adobe Flash Professional CS6. The application was chosen as product creation because it has complete features with neat menu preparation, making it easy to create interesting animations by organizing them through the features available in the software. In addition, Adobe Flash 
Professional CS6 facilitates the efficiency of animations, ranging from moving effects, embossed effects and other effects. The main advantage of Adobe Flash Professional CS6 is that it can create actionscript as needed which can speed up the researcher's performance process in editing animations.

3) Multimedia development contains discrimination learning materials and early childhood education curriculum in Indonesia: The first step taken in designing the product design researchers pay attention to the discrimination learning stages of Erwin. E Gordon which contains the Solfeggio method, this stage by researchers is used as a benchmark in the determination of the level of the game, namely the aural/oral stage, verbal association, and partial synthesis [13,14].

The aural/oral stage is conditioned in more detail into two parts, namely sound discrimination by presenting several types of animal sounds, vehicle sounds and musical instrument sounds to give the child the opportunity to be able to distinguish the distinctive sound from each using sound, then identify the sound by comparing two types of animal sounds to give the opportunity to be able to identify the number of sounds and be able to distinguish high-low sounds. Then the verbal association stage is conditioned by presenting the notation associated with the syllable of an object representing half notes, quarter notes and one-eighth notts. While the partial synthesis stage is reconciled by presenting notation analogous to symbols that children must simulate both sound and motion.

Then researchers adapted it by adapting the game content to the Standard Child Development Attainment Level and child development tasks. In addition, the material in Aurilio Games refers to the Curriculum of early childhood education in Indonesia $[15,16]$.

4) Accompaniment music in aurilio games made through sibelius software: Sibelius software serves to write score notation so that it will later produce accompaniment music as needed and can be converted into mp3 form. This software has a variety of instruments, both melodic intrusion such as piano, harmonica and others and there are rhythmic instruments that are very much loved by early childhood, such as drum sets, triangles, tambourine, and many more.

5) Character and background game created through corel draw software: Corel Draw software serves to design and edit images so that they will later produce two-dimensional images as needed and can be converted into JPG, PNG, etc. shapes. The software has features, geometric symbols and diverse colors making it easier for researchers to create characters and backgrounds according to previously designed sketches. In addition, the resulting two-dimensional image can give rise to a cartoon effect that children love when input into animation maker software.

6) Combining audio recording with metronome created through audacity software: Audacity software serves to process audio in digital form, either combine, trim, set highlow audio, set sound contrast, etc. In this development, researchers used audacity software to combine dubbing audio with metronome sound so that the sound fused into a clear unity in the hearing and in accordance with the beats contained in metronome. The resulting file of this software can be converted into MP3 format so that it can be inputt into the animation maker software used by researchers.

\section{B. Product Implementation}

Product implementation was carried out in two class groups, with a total of 26 children and 2 classroom teachers. Product is a learning medium in the form of educative game application used to facilitate ear training that develops auditory and verbal aspects of early childhood. Products are equipped with learning scenarios, handbooks for teachers and parents and observation guidelines to evaluate game results. The product consists of three levels, which can stimulate the ability to identify sounds, discriminate against sounds and simulate sounds through both sound and movement.

The use of aurilio games is carried out from the beginning of learning through teacher guidance in accordance with the learning scenarios that have been provided. Learning is beginning with an opening activity containing habituation of praying and others. Then the teacher performs aperception by inviting the child to sing and follow the song movement that has been provided. After that, in the core activities, the teacher invites and guides the child to complete all the levels in the game aurilio by first presenting the material contained in the material menu in the Aurilo Game. Children perform Aurilio Games according to the direction and guidance of the teacher. When the game ends, the teacher gives appreciation to the child and invites the child to rest and have lunch together. Then, in the closing activities, the teacher motivates the child to apply the learning obtained after playing the Aurilio Game in daily life and invites the child to read the poems together that have been provided in the Aurilio Game Learning Package. During the learning process, the observer conducts observations to find out the achievement of the child's ear training skills. At the end of the lesson the classroom teacher is given a questionnaire to respond to the usability aspect of the game that has been used.

Here are the observations of the child's ear training skills and the teacher's response to the use of aurilio games:

TABLE I. RECAPITULATION OF EARLY CHILDHOOD EAR TRAINING OBSERVATION RESULTS

\begin{tabular}{|l|l|c|c|c|c|c|c|}
\hline \multirow{2}{*}{ School } & \multicolumn{5}{|c|}{ Aspect } & AMT & \% \\
\cline { 2 - 8 } & $\mathbf{1}$ & $\mathbf{2}$ & $\mathbf{3}$ & $\mathbf{4}$ & $\mathbf{5}$ & & \\
\hline School A & $88 \%$ & $95 \%$ & $67 \%$ & $52 \%$ & $45 \%$ & $347 \%$ & $69 \%$ \\
\hline School B & $75 \%$ & $75 \%$ & $78 \%$ & $61 \%$ & $72 \%$ & $361 \%$ & $72 \%$ \\
\hline AMOUNT & $163 \%$ & $170 \%$ & $145 \%$ & $113 \%$ & $117 \%$ & $708 \%$ & $142 \%$ \\
\hline$\%$ & $82 \%$ & $85 \%$ & $73 \%$ & $57 \%$ & $59 \%$ & $71 \%$ & \\
\hline
\end{tabular}

Description:

1: Aspects of discriminating against sound

2: Aspects of identifying sounds

3: Aspects of assimilating syllables

4: Aspects of simulating symbols through sound

5: Aspects of simulating symbols through gestures 
TABLE II. RECAPITULATION OF TEACHER'S RESPONSE TO AURILIO GAME USABILITY ASPECT

\begin{tabular}{|c|c|c|c|c|}
\hline Statement & R1 & R2 & AMT & $\%$ \\
\hline 1 & 5 & 7 & 12 & $86 \%$ \\
\hline 2 & 6 & 7 & 13 & $93 \%$ \\
\hline 3 & 4 & 7 & 11 & $79 \%$ \\
\hline 4 & 4 & 7 & 11 & $79 \%$ \\
\hline 5 & 4 & 7 & 11 & $79 \%$ \\
\hline 6 & 4 & 7 & 11 & $79 \%$ \\
\hline 7 & 5 & 7 & 12 & $86 \%$ \\
\hline 8 & 4 & 7 & 11 & $79 \%$ \\
\hline 9 & 3 & 7 & 10 & $71 \%$ \\
\hline 10 & 5 & 7 & 12 & $86 \%$ \\
\hline 11 & 6 & 7 & 13 & $93 \%$ \\
\hline 12 & 5 & 7 & 12 & $86 \%$ \\
\hline 13 & 5 & 7 & 12 & $86 \%$ \\
\hline 14 & 5 & 7 & 12 & $86 \%$ \\
\hline 15 & 7 & 7 & 14 & $100 \%$ \\
\hline 16 & 7 & 7 & 14 & $100 \%$ \\
\hline 17 & 5 & 7 & 12 & $86 \%$ \\
\hline 18 & 5 & 7 & 12 & $86 \%$ \\
\hline 19 & 4 & 7 & 11 & $79 \%$ \\
\hline 20 & 6 & 7 & 13 & $93 \%$ \\
\hline 21 & 6 & 7 & 13 & $93 \%$ \\
\hline 22 & 7 & 7 & 14 & $100 \%$ \\
\hline AMT & 122 & 154 & 266 & \multirow{2}{*}{$86 \%$} \\
\hline$\%$ & $73 \%$ & $100 \%$ & $173 \%$ & \\
\hline
\end{tabular}

\section{Description:}

1 : Overall, I am satisfied with the ease of use of Aurilio Games

2: How to use Aurilio Game is very simple

3: I can meet my needs (about early childhood ear-training learning) more easily using this Aurilio Game

4: I was able to meet my needs (about early childhood eartraining) faster using this Aurilio Game

5: I can meet my needs (about early childhood ear-training learning) more efficiently using this Aurilio Game

6: I feel comfortable using this Aurilio Game

7: This Aurilio game is very easy to learn

8: I'm sure it will be more productive when using this Aurilio Game

9: This Aurilio game gives a clear error message and tells you how to solve it

10: Every time I make a mistake in playing this Aurilio Game, I can cope quickly and easily

11: The information provided by Aurilio Game is quite clear

12: It's easy to find the information needed in this Aurilio Game

13: The information provided by Aurilio Game is very easy to understand

14: The information provided is easy to help complete this Aurilio Game

15: The layout of the information displayed on the Aurilio Game screen is clear

16: Aurilio's Game View is fun

17: I like to use the look of games like this

18: Aurilio game has the functionality and capabilities as I expected

19: Overall, I am satisfied with this Aurilio Game
20: The language in the guidebook is easy to understand

21: Clear manual guidebook order

22: Interesting guidebook view

The defense of music using aurilio games appears to facilitate the auditory and verbal abilities of children, especially stimulating ear training skills, ranging from identifying sounds, discriminating against sounds and simulating sounds. Teachers are also becoming more likely to present interesting music learning to early childhood who previously found it difficult and tended to be monotonous. Thus, music learning in early childhood by using aurilio games becomes more effective in facilitating ear training as the basic capital of children's musical abilities as well as more innovative with multimedia-based music learning on learning.

\section{CONCLUSION}

The development of aurilio games as a music learning medium for early childhood is based on the needs of the field. In addition, aurilio games are integrated and adapted to the 2013 curriculum of Early Childhood Education and the stages of child development. Armed with learning scenarios and handbooks, the application of aurilio games in music learning for early childhood can be done in accordance with the learning in general, where aurilio games are very helpful for children in stimulating the ability to identify sounds, discriminate against sounds and simulate sounds through sound and movement. The usability aspect of this game can work well. Based on the implementation that has been done by researchers, shows that by using aurilio games in music learning, it can facilitate children to have ear training skills that develop auditory and verbal aspects of early childhood.

\section{REFERENCES}

[1] H.D. Marshall and J.M. Bailey, "Observing and communicating early childhood music and movement development," Perspectives: Journal of the Early Childhood Music \& Movement Association, vol. 4, no. 1, pp. 14-20, 2009.

[2] R. Respati, Pengembangan Bahan Ajar Solfeggio Untuk Mahasiswa Pendidikan Guru Sekolah Dasar. (Tesis). Program Studi Pendidikan Seni Sekolah Pascasarjana UPI Bandung, 2012.

[3] E.F. Türkmen and I.O. Göncü, "The Challenges Encountered in the Application of Kodaly Method in Turkey," Journal of Education and Training Studies, vol. 6, no. 9, pp. 39-45, 2018.

[4] S.R. Rekha, "Tapping into Technology: Experiencing Music in a Child's Digital World," National Association for Music Education, vol. 28, no. 1, pp. 8-11, 2014.

[5] K. Scheiter, A. Schüler, P. Gerjets, T. Huk and F.W. Hesse, "Extending Multimedia Research: How Do Prerequisite Knowledge and Reading Comprehension Affect Learning From Text And Pictures," Computers in Human Behavior, vol. 31, no. 5, pp. 73-84, 2014.

[6] W. Tsou, W. Wang, and Y. Tzeng, "Applying a multimedia storytelling website in foreign language learning," Computers \& Education, vol. 47, no. 1 , pp. $17-28,2006$.

[7] S. Aminah, "Pengaruh Musik Islami terhadap Perkembangan Bahasa Anak," EL-BANAT: Jurnal Pemikiran dan Pendidikan Islam, vol. 6, no. 2, pp. 92-101, 2016.

[8] T. Amiel and T.C. Reeves, "Design-Based Research and Educational Technology: Rethinking Technology and the Research Agenda," Educational Technology \& Society, vol. 11, no. 4, pp. 29-40, 2008. 
[9] H.D. Anderson, Dale's Cone of Experience. Kentucky: University of Kentucky, 2015.

[10] K.B. Bagley, The Kodaly Method: Standardizing Hungarian Music Education. Mississippi: University of Mississippi Zoltan Kodaly Pedagogical, 2005.

[11] Z. Kiraly, "Solfeggio 1: A Vertical Ear Training Instruction Assisted by the Computer," International Journal of Music Education, vol. 2, no. 1, pp. 41-58, 2003.

[12] Q. Zhou and B. Yan, "Music Solfeggio Learning Platform Construction and Application," International Journal of Emerging Technologies in Learning (iJET), vol. 12, no. 12, pp. 14-23, 2017.
[13] E.E. Gordon, "Audiation, Music Learning Theory, Music Aptitude, and Creativity," In Suncoast music education forum on creativity, vol. 75, no. $81,1989$.

[14] The Gordon Institute for Music Learning, Early Childhood [Online] Accessed from: https://giml.org/mlt/earlychildhood/, 2018

[15] Regulation of the Minister of Education and Culture of the Republic of Indonesia No.137 of 2014 on National Standards of Early Childhood Education. Jakarta: Ministry of Education.

[16] Regulation of the Minister of Education and Culture of the Republic of Indonesia No.146 of 2014 on curriculum 2013 early childhood education. Jakarta: Ministry of Education. 